\title{
DESAIN SPATULA ERGONOMIS MENGGUNAKAN PENDEKATAN MODEL KANO
}

\author{
Rustam Sidiq ${ }^{1}$, Hari Purnomo ${ }^{2}$ \\ Magister Teknik Industri, Fakultas Teknologi Industri, Universitas Islam Indonesia ${ }^{1,2)}$ \\ Jl Kaliurang KM 14,5, Sleman, Yogyakarta, 55584 \\ E-Mail : sidiqrustam@gmail.com ${ }^{1}$, haripurnomo134@gmail.com ${ }^{2}$
}

\begin{abstract}
Occupational accidents often occur in the workplace kitchens, one of which was during the times of frying. During frying one of the tools that cause accidents are prone spatula, then from it in carefully designed spatula which can reduce the risk of injury is based on the experience of the spatula by the user. Kano on the method used to determine the level of user satisfaction to the user experience in the use of a product. From other research on get 4 attribute that affects the user's satisfaction spatula users are safe from the stepping oil, spatula attributes not easily conduct heat, attributes spatula material is non-flammable and attributes spatula comfortable grip. Then make a proposal spatula design for the user, that is spatula design with hand protector, use of raw materials falcata wood combined with stainlees steel and approach anthropometric calculations to determine the amount of the dimensions of the proposed design spatula. So with spatula design in the proposal it is expected spatula able to provide security and comfort when in use by the user.
\end{abstract}

Keywords : Kitchen, Spatula, Kano Model, Design.

\section{PENDAHULUAN}

Aktivitas di dapur berpotensi terhadap terjadinya kecelakaan kerja. Kecelakaan yang sering terjadi di dapur diakibatkan karena pengaplikasian ergonomi yang kurang baik (Mondal, 2012). Pada saat memasak seseorang sering terkena alat memasak yang panas seperti penggorengan yang menyebabkan risiko cedera (Jeong, 2015; HSE, 2015). Salah satu alat masak yang jarang dikaji adalah spatula. Sedangkan spatula yang tidak didesain dengan baik dan tidak ergonomis menyebabkan cedera pada tangan (Wu and Hsieh, 2002). Oleh karena itu, perlu dirancang produk spatula untuk pengembangan produk. Pengembangan produk baru merupakan tugas kompleks dengan melibatkan sumber daya manusia, metode dan alat-alat yang terlibat (Rashid, et al., 2010; Roper, et al., 2015). Keberhasilan pengembangan produk terletak pada pemenuhan keinginan pemakai produk (Djatna, et al., 2015; Abdolmaleki dan Ahmadian, 2016). Rashid, et al., (2010) menjelaskan bahwa kebutuhan pelanggan merupakan komponen penting dari pengembangan produk baru. Berdasarkan permasalahan dan pentingnya pengguna dalam perancangan, maka penelitian ini digunakan metode Kano.

Model Kano merupakan sebuah metode yang fokus mengembangkan produk berdasarkan atribut berdasarkan kepuasan konsumen terhadap atribut fungsional produk (Sauerwein, et al., 1996; MacDonald, at al., 2006; Narang and Albayyari, 2009; Rashid, 2010; Taifa dan Desai, 2015). Banyak studi tentang desain yang dikembangkan dengan model kano, seperti perancangan atribut yang dibutuhkan dalam pengembangan desain mobil (Rashid, et al., 2010), pengembangan desain produk berlian berdasarkan kepuasan konsumen (Biglia, et al., 2011), pengembangan desain stasiun kerja yang ergonomis berdasarkan tingkat kepuasan pemakai (Hasyim and Dawal, 2012), pengembangan desain produk smart pads menggabungkan preferensi pelanggan dan persepsi ke dalam proses pengembangan produk (Wang and Hsueh, 2013), pengembangan desain souvenir keramik dengan model kano dan kansei engineering (Tama, et al., 2015). 
Dari beberapa penelitian diatas masih belum banyak penelitian dengan obyek alat masak dengan inovasi sederhana yang mudah diaplikasikan. Tujuan penelitian ini adalah merancang spatula yang ergonomis untuk meminimasi kecelakaan kerja pada saat menggoreng, sehingga dapat meningkatkan produktivitas bagi pengguna.

\section{METODE PENELITIAN}

\subsection{Obyek Penelitian}

Obyek pada penelitian ini adalah spatula sebagai alat bantu menggoreng. Desain spatula terdiri dari 2 bagian yaitu bagian badan spatula yang berfungsi sebagai pegangan dan bagian kepala depan berfungsi sebagai bagian untuk membalik benda yang di goreng. Spatula pada umumnya terdiri dari 2 tipe yaitu spatula dengan berbahan dasar kayu dan spatula dengan berbahan dasar besi. Pada penelitian ini dua tipe spatula ini digunakan sebagai referensi pembanding.

\subsection{Populasi dan Sampel}

Sebelum melakukan penelitian, terlebih dahulu ditentukan sampel dari populasi. Karena jumlah populasi ibu-ibu pengguna spatula sangat besar, maka penentuan jumlah sampel minimum untuk pemakai ditentukan dengan rumus (Supranto, 2001):

$n=\frac{1}{4}\left(\frac{z^{\alpha / 2} / 2}{E}\right)^{2}$

$\mathrm{n}=$ Jumlah sampel dari populasi yang ingin di peroleh.

$z=$ Angka yang menunjukkan penyimpangan nilai varians dari mean.

$E=$ Limit dari error atau presisi absolut.

$\alpha=$ Tingkat kesalahan data yang dapat ditoleransi oleh peneliti.

Apabila tingkat kepercayaan 95\% dan batas erorr 10\%, maka besarnya sampel minimum 96 responden.

\subsection{Jenis Data}

Jenis data yang diperlukan dalam penelitian adalah ini:

1) Data Primer. Data yang didapat dari wawancara dan hasil penyebaran kuesioner kepada pengguna spatula terhadap atribut kebutuhan produk spatula.

2) Data Sekunder. Data yang di dapat dari artikel yang terkait dengan desain produk dan spatula.

\subsection{Prosedur Penelitian}

\subsection{Tahap Persiapan}

Pada tahap ini dilakukan langkahlangkah sebagai berikut:

a. Observasi terhadap obyek yang diteliti serta identifikasi terhadap kelemahankelemahan produk lama.

b. Menyiapkan alat dan bahan yang digunakan dalam penelitian.

c. Menyusun kuesioner yang akan disebarkan kepada pemakai spatula untuk menangkap kebutuhan produk spatula.

\subsubsection{Tahap Pelaksanaan}

Pelaksanaan penelitian dilakukan dengan tahapan sebagai berikut :

a. Wawancara dengan pengguna terkait dengan keinginan dan harapan penguna terhadap spatula yang dipakai.

b. Menyebarkan kuesioner untuk mengukur keinginan pengguna tentang produk spatula.

c. Menterjemahkan hasil kuesioner ke grafik kano dan membuat usulan produk dari hasil terjemahan grafik kano.

\subsubsection{Tahap Desain}

Dalam tahap ini dilakukan desain spatula dengan pendekatan model kano. Metode kano merupakan konsep untuk mengetahui kompleksitas kebutuhan pengguna dan hubungan mereka dengan kepuasan penggunaan produk yang di terjemahkan dalam format grafis (Narang and Albayyari, 2009). Langkah-langkah implementasi model kano adalah (Narang and Albayyari, 2009): 
Tabel 1. Evaluasi kuesioner Kano

\begin{tabular}{cccccc}
\hline & \multicolumn{5}{c}{ Disfunctional } \\
\cline { 2 - 6 } Functional & Suka & Mengharapkan & Netral & $\begin{array}{c}\text { Memberikan } \\
\text { Toleransi }\end{array}$ & $\begin{array}{c}\text { Tidak } \\
\text { Suka }\end{array}$ \\
\hline Suka & $\mathrm{Q}$ & $\mathrm{A}$ & $\mathrm{A}$ & $\mathrm{A}$ & $\mathrm{O}$ \\
Mengharapkan & $\mathrm{R}$ & $\mathrm{I}$ & $\mathrm{I}$ & $\mathrm{I}$ & $\mathrm{M}$ \\
Netral & $\mathrm{R}$ & $\mathrm{I}$ & $\mathrm{I}$ & $\mathrm{I}$ & $\mathrm{M}$ \\
$\begin{array}{c}\text { Memberikan } \\
\text { toleransi }\end{array}$ & $\mathrm{R}$ & $\mathrm{I}$ & $\mathrm{I}$ & $\mathrm{I}$ & $\mathrm{M}$ \\
Tidak suka & $\mathrm{R}$ & $\mathrm{R}$ & $\mathrm{R}$ & $\mathrm{R}$ & $\mathrm{Q}$ \\
\hline
\end{tabular}

a. Mengumpulkan data kuesioner

Kuesioner yang disusun dilakukan uji coba untuk mengetahui pendapat terhadap atribut kebutuhan pengguna produk spatula. Pengumpulan data dari kuesioner dengan mempertimbangkan kebutuhan produk secara fungsional yaitu keberadaan atribut pada produk spatula dan pendapat penggunaan jika atribut produk tersebut tidak ada. Hasil kuesioner selanjutnya dilakukan pemetaan antara jawaban dan status atribut. Pemetaan ditunjukkan seperti pada Tabel 1. Enam kategori pada Tabel 1 diatas, dijelaskan sebagai berikut :

1. A (Attractive), menjelaskan bahwa kepuasan pengguna akan meningkat jika produk berfungsi lebih baik dari biasanya dan kepuasan pengguna tidak turun meskipun produk berfungsi lebih baik.

2. M (Must-be), menjelaskan bahwa semakin produk tidak berfungsi seperti biasanya, maka terjadi penurunan kepuasan pengguna dan tidak terjadi peningkatan kepuasan pengguna walaupun produk berfungsi sangat baik.
3. (One-dimensional), menjelaskan jika produk semakin berfungsi dengan baik maka kepuasan pengguna akan meningkat. Sebaliknya, jika produk tidak berfungsi dengan semestinya maka terjadi penurunan kepuasan pengguna.

4. I (Indifferent), menjelaskan bahwa kepuasan pengguna tidak dipengaruhi oleh sifat produk yang fungsional atau tidak fungsional.

5. $\mathrm{R}$ (Reverse), menjelaskan bahwa fungsi sebuah produk berlawanan dengan yang dirasakan oleh pengguna.

6. Q (Questionable), menjelaskan bahwa jawaban pengguna tidak sesuai dengan pertanyaan.

b. Mengevaluasi data kuesioner dengan tabel evaluasi kano

Perhitungan frekuensi kategori kano dilakukan untuk setiap atribut produk dan digolongkan menggunakan formula Blauth's dengan ketentuan adalah : 
Tabel 2. Hasil uji reliabilitas

Functional question

Disfunctional question
0,731

5

0,872

5

Tabel 3. Hasil uji statistik validitas

\begin{tabular}{c|c|c|c}
\hline $\begin{array}{c}\text { Functional } \\
\text { Question }\end{array}$ & $\begin{array}{c}\text { Corrected Item } \\
\text { total } \\
\text { Correlation }\end{array}$ & $\begin{array}{c}\text { Disfunctional } \\
\text { Question }\end{array}$ & $\begin{array}{c}\text { Corrected Item total } \\
\text { Correlation }\end{array}$ \\
\hline Butir Pertanyaan 1 & 0.472 & Butir Pertanyaan 1 & 0.864 \\
Butir Pertanyaan 2 & 0.542 & Butir Pertanyaan 2 & 0.565 \\
Butir Pertanyaan 3 & 0.504 & Butir Pertanyaan 3 & 0.837 \\
Butir Pertanyaan 4 & 0.387 & Butir Pertanyaan 4 & 0.700 \\
Butir Pertanyaan 5 & 0.640 & Butir Pertanyaan 5 & 0.670 \\
\hline
\end{tabular}

1. Apabila frekuensi untuk kategori $(\mathrm{O}$ $+\mathrm{A}+\mathrm{M})>(\mathrm{I}+\mathrm{R}+\mathrm{Q})$, maka grade yang diperoleh adalah nilai maksimum dari (O, A, M).

2. Apabila frekuensi untuk kategori $(\mathrm{O}$ $+\mathrm{A}+\mathrm{M})<(\mathrm{I}+\mathrm{R}+\mathrm{Q})$, maka grade yang diperoleh adalah nilai maksimum dari (I, R, Q).

Selanjutnya menghitung Customer Satisfaction Coefficient (CSC) dengan rumus sebagai berikut :

$\mathrm{SI}=\frac{\mathrm{A}+\mathrm{O}}{\mathrm{A}+\mathrm{O}+\mathrm{M}+\mathrm{I}} \quad \mathrm{DI}=-\frac{M+O}{A+O+M+I}$.

Dimana :

$\mathrm{SI}=$ Satisfaction Index

DI = Disatisfaction Index .
Setelah nilai SI dan DI diketahui, kemudian digambarkan dalam grafik koefisien kepuasan kano. Sumbu X adalah nilai DI dan sumbu Y adalah nilai SI. Desain usulan hasil interpretasi grafik kepuasan kano diketahui gambaran tentang atribut produk yang dianggap penting oleh pengguna, sehingga peneliti bisa fokus pada fitur produk yang akan membedakan produk yang dibuat dengan produk yang sudah ada.

\section{HASIL DAN PEMBAHASAN 3.1. Uji validitas dan reliabilitas}

Identifikasi tingkat kepuasan konsumen dilakukan wawancara dan penyebaran kuisioner kepada 100 pengguna spatula dengan mengajukan pertanyaan berdasarkan kepuasan desain spatula berdasarkan penentuan kategori kano dengan 5 atribut. 
Tabel 4. Hasil frekuensi kategori Kano

\begin{tabular}{l|c|c|c|c|c|c|c}
\hline \multicolumn{1}{c|}{ Atribut Produk } & A & O & M & I & R & Q & Total \\
\hline Spatula aman dari semburan minyak. & 42 & 32 & 10 & 10 & 6 & 0 & 100 \\
Spatula tidak mudah menyalurkan panas. & 27 & 19 & 35 & 19 & 0 & 0 & 100 \\
Bahan spatula tidak mudah terbakar. & 25 & 19 & 31 & 22 & 3 & 0 & 100 \\
Desain spatula bisa multifungsi. & 19 & 23 & 16 & 35 & 7 & 0 & 100 \\
Spatula nyaman di genggam. & 27 & 29 & 25 & 19 & 0 & 0 & 100 \\
\hline
\end{tabular}

Tabel 5. Nilai CSC atribut desain spatula

\begin{tabular}{lcccccccccc}
\multicolumn{1}{c}{ Atribut Produk } & $\mathbf{A} \%$ & $\mathbf{O} \%$ & $\mathbf{M} \%$ & $\mathbf{I} \%$ & $\mathbf{R} \%$ & $\mathbf{Q} \%$ & $\begin{array}{c}\text { Total } \\
\%\end{array}$ & SI & DI \\
\hline $\begin{array}{l}\text { Spatula aman dari } \\
\text { semburan minyak. }\end{array}$ & 42 & 32 & 10 & 10 & 6 & 0 & 100 & 0.78 & -0.44 \\
\hline $\begin{array}{l}\text { Spatula tidak mudah } \\
\text { menyalurkan panas. }\end{array}$ & 27 & 19 & 35 & 19 & 0 & 0 & 100 & 0.46 & -0.54 \\
\hline $\begin{array}{l}\text { Bahan spatula tidak } \\
\text { mudah terbakar. }\end{array}$ & 25 & 19 & 31 & 22 & 3 & 0 & 100 & 0.45 & -0.51 \\
\hline $\begin{array}{l}\text { Desain spatula bisa } \\
\text { multifungsi. }\end{array}$ & 19 & 23 & 16 & 35 & 7 & 0 & 100 & 0.45 & -0.41 \\
\hline $\begin{array}{l}\text { Spatula nyaman di } \\
\text { genggam. }\end{array}$ & 27 & 29 & 25 & 19 & 0 & 0 & 100 & 0.56 & -0.56 \\
\hline
\end{tabular}

Untuk memastikan hasil kuesioner telah memenuhi syarat dapat digunakan sebagai data penelitian dilakukan uji reliabilitas kuesioner. Hasil uji reliabilitas ditunjukkan pada Tabel 2. Pada Tabel 2 tersebut nilai Cronbach's Alpha>0,7 atau sebesar 0,731 untuk Functional question dan 0.872 untuk Disfunctional question. Hal ini menunjukan bahwa data tersebut reliabel.

Sedangkan uji validitas dapat dilihat pada Tabel 3. Hasil pengujian validitas terlihat bahwa semua butir pertanyaan pada functional question dan disfunctional question berada di atas nilai table $\mathrm{r}$ dengan taraf signifikan 5\% $(>0,195)$ sehingga semua butir pertanyaan yang ada pada kuesioner kano dalam penelitian ini dinyatakan valid.

\subsection{Identifikasi kepuasan konsumen}

Identifikasi kepuasan konsumen didapat dari penyebaran kuesioner tentang desain spatula dan wawancara dengan pengguna. Pilihan produk oleh konsumen dilakukan dengan cara mengkombinasikan hasil functional dan disfunctional menghitung frekuensi kategori kano. Selanjutnya menentukan nilai SI dan DI dengan melakukan perhitungan Customer Satisfaction Coefficient (CSC). Kategori frekuensi kategori kano ditunjukkan pada Tabel 4.

Hasil perhitungan nilai CSC seperti pada Tabel 5 diketahui besarnya nilai SI dan DI pada tiap atribut. Nilai SI memperlihatkan bahwa pengaruh kehadiran suatu atribut terhadap kepuasan pengguna akan semakin besar jika mendekati nilai 1, sedangkan DI memperlihatkan bahwa pengaruh 
ketidakhadiran atribut terhadap ketidakpuasan konsumen akan semakin tinggi jika mendekati nilai -1 .

\subsection{Grafik Model Kano}

Nilai SI dan DI dimasukan ke dalam grafik model Kano. Gambar 1 adalah posisi atribut produk. Berdasarkan Gambar 1 dapat dijelaskan bahwa atribut 1 yaitu spatula aman dari semburan minyak termasuk dalam kategori attractive. Atribut tersebut memiliki nilai SI sebesar 0,78. Nilai tersebut menunjukkan jika spatula memberikan rasa aman, maka semakin kuat pengaruh terhadap kepuasan konsumen. Sedangkan pada atribut ke 2 yaitu atribut spatula tidak menyalurkan panas dan atribut ke 3 yaitu atribut bahan spatula tidak mudah terbakar masuk ke dalam kategori must be. Hal ini menjelaskan bahwa desain spatula yang tidak menyalurkan panas dan tidak mudah terbakar sangat dibutuhkan oleh konsumen. Jika atribut tersebut tidak ada maka menimbulkan ketidakpuasan. Desain spatula yang multifungsi yaitu atribut ke 4 masuk kategori Indifferent.

Pada kasus ini, spatula yang multifungsi tidak berpengaruh terhadap kepuasan pengguna. Atribut ke 5 yaitu spatula yang nyaman digenggam masuk dalam kategori one dimensional. Dengan demikian penambahan atribut ini sangat diperlukan oleh konsumen. Hasil dari grafik kano spatula didapatkan atribut 1 berada dikategori attractive. Untuk itu perlu dihadirkan usulan pengembangan produk yang bisa melindungi tangan pengguna dari semburan minyak panas agar kepuasan pengguna meningkat. Dari atribut tesebut diusulkan menambahkan pelindung pada gagang spatula yang berbahan dasar kain katun untuk melindungi tangan pengguna spatula dari semburan minyak panas. Bahan dasar kain katun TC (Teteron Cotton) memiliki kelebihan yaitu tetap nyaman digunakan walaupun saat cuaca panas, karena mudah menyerap keringat. Selain itu untuk pelindung tangan pada spatula didesain dengan posisi bukaan diatas untuk memudahkan melepas pelindung. Untuk membuka dan menutup dipakai perekat dan tangan bisa masuk lewat lubang belakang sebagai fungsi tambahan tempat masuk tangan ke pelindung spatula.

Sedangkan untuk atribut 2 dan 3 masuk kategori must be. Atribut ke 2 yaitu spatula tidak mudah menyalurkan panas di usulkan menggunakan bahan kayu pada bagian badan spatula atau pegangan. Pemilihan kayu agar tangan pengguna tetap aman dari panas yang menjalar. Untuk atribut ke 3 yaitu bahan spatula tidak mudah terbakar di usulkan untuk bagian depan spatula yang bersentuhan langsung dengan penggorengan digunakan stainless steel. Hal ini dikarenakan bagian depan spatula langsung bersentuhan dengan wajan yang sangat rentan terbakar dan rusak akibat terkena sambaran api dari kompor. Pemilihan besi stainless steel karena dapat mengurangi kerusakan akibat terkena sambaran api. Selain itu stainless tidak mudah berkarat sehingga aman bagi bahan dasar alat pengolahan makanan. Atribut ke 5 desain spatula yang nyaman digenggam masuk ke dalam kategori one dimensional. Oleh karena itu, untuk atribut ke 5 agar memenuhi kepuasan pengguna diusulkan dimensi genggaman badan spatula disesuaikan dengan antropometri tangan dan pemakaian bahan baku dari kayu yang ringan dan mudah digenggam. Untuk atribut ke 4 yaitu desain spatula yang multifungsi masuk kedalam kategori indifferent yang tidak berpengaruh apapun ketika atribut ini dimasukkan ke dalam desain produk. Dengan demikian atribut ini tidak perlu dimasukkan ke dalam usulan desain produk. Desain usulan spatula dapat dilihat pada Tabel 6 berikut. 
Tabel 6. Desain usulan spatula

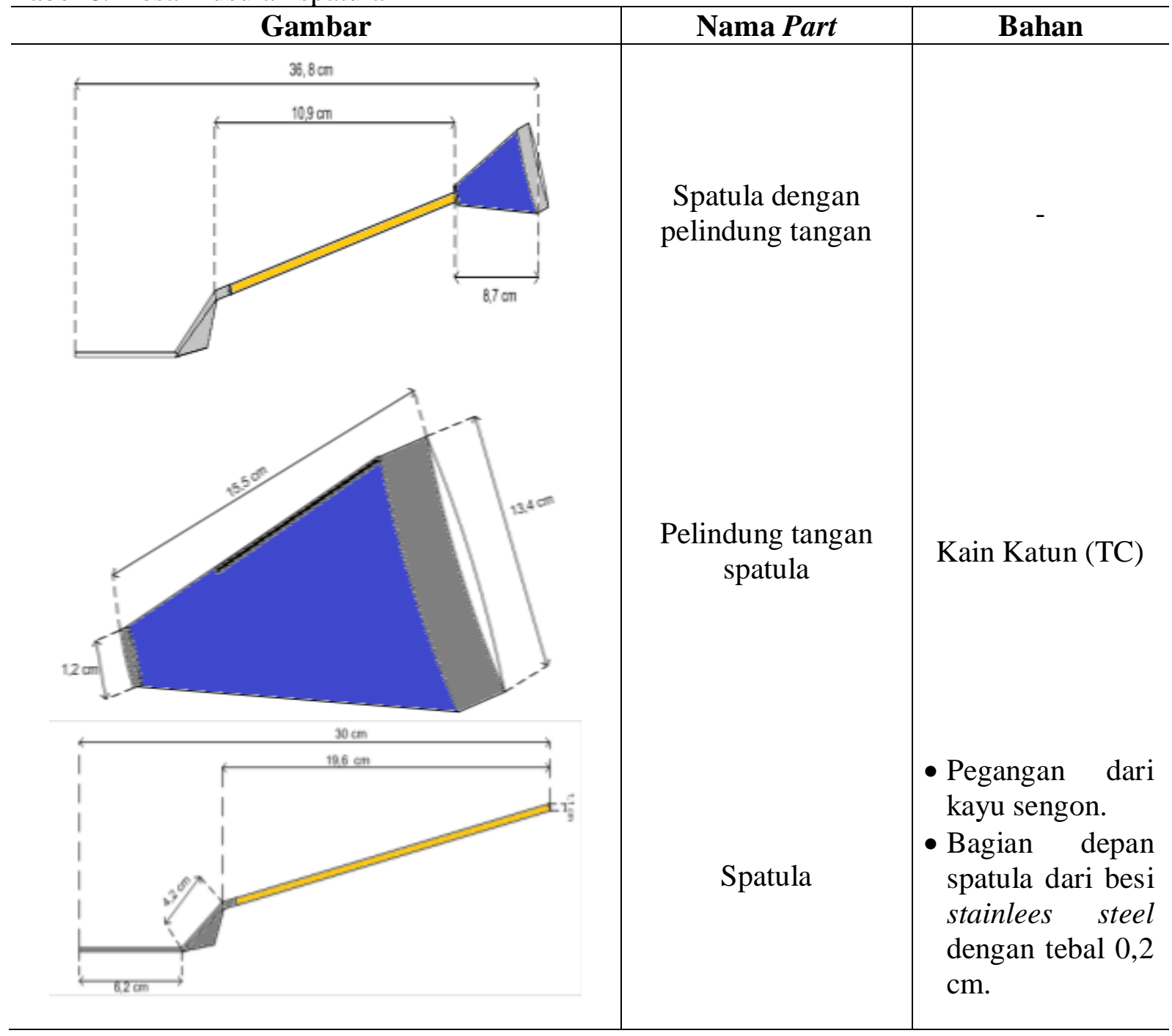

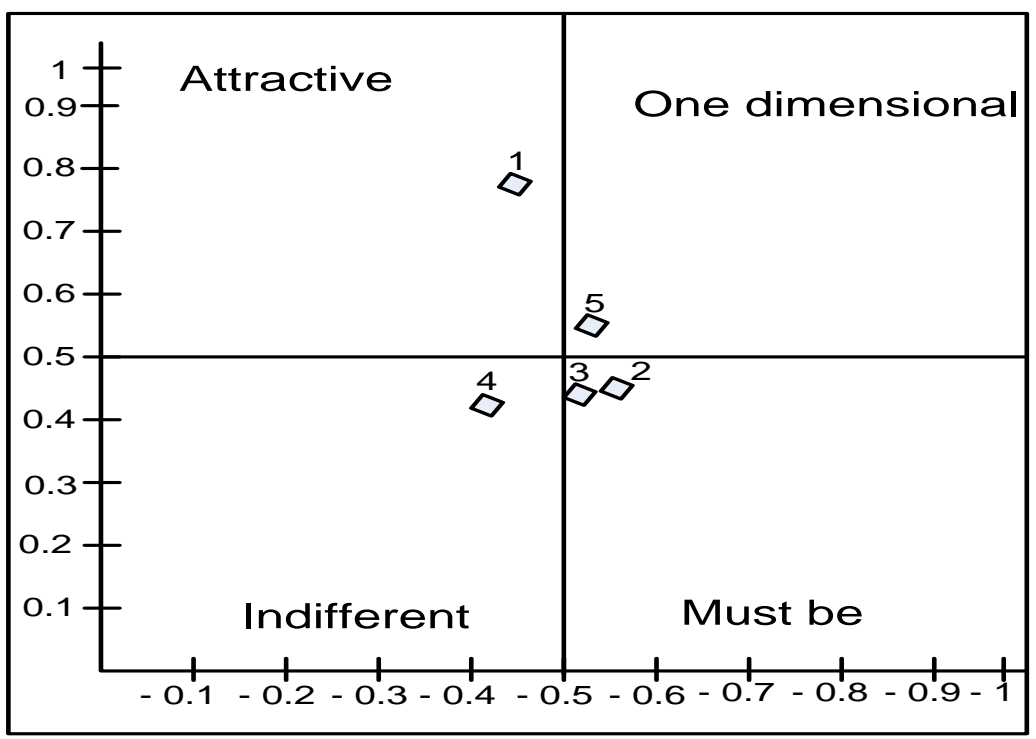

Gambar 1. Grafik atribut spatula. 
Perwujudan desain usulan spatula di atas terdapat ukuran dengan dasar penentuan dimensi alat sebagai berikut:

\section{Dimensi spatula}

a. Panjang keseluruhan spatula $30 \mathrm{~cm}$, diambil dari spatula yang di jadikan perbandingan dalam penelitian ini.

b. Panjang bagian depan spatula adalah lebar 4,2 cm dan panjang $6,2 \mathrm{~cm}$. Dimensi ini di ambil dari spatula yang dijadikan perbandingan dalam penelitian.

c. Diameter badan spatula $1,1 \mathrm{~cm}$. Dimensi ini didasarkan dari antropometri dari diameter genggaman minimum untuk wanita Indonesia dengan nilai persentil ke 5 yaitu sebesar $1,07 \mathrm{~cm}$.

\section{Dimensi pelindung tangan spatula}

a. Panjang pelindung tangan spatula 15,5 $\mathrm{cm}$. Dimensi didasarkan pada antropometri panjang tangan wanita Indonesia dengan nilai persentil ke 5 .

b. Diameter lubang belakang pelindung $13,4 \mathrm{~cm}$ diambil dari antropometri lebar fungsional maksimum tangan wanita Indonesia dengan persentil ke 95.

c. Diameter lubang depan pelindung 1,2 $\mathrm{cm}$. Dimensi diambil dari besarnya diameter badan spatula ditambahkan allowance $0,1 \mathrm{~cm}$.

\section{Dimensi total desain usulan spatula}

a. Peletakan pelindung pada badan spatula diletakkan di $8,7 \mathrm{~cm}$ dari ujung atas badan spatula. Hal ini didasarkan pada lebar telapak tangan wanita Indonesia dengan persenti ke 5 .

b. Total keseluruhan desain usulan spatula adalah $30 \mathrm{~cm}+15,5 \mathrm{~cm}-8,7$ $\mathrm{cm}=36,8 \mathrm{~cm}$.

\section{KESIMPULAN}

Berdasarkan hasil penelitian terdapat 1 atribut masuk kategori attractive, 2 atribut masuk kategori must be, 1 atribut masuk kategori one dimensional dan 1 atribut masuk dalam kategori indifferent. Perancangan spatula tersebut terdapat 4 atribut yang di gunakan sebagai bahan pertimbangan perbaikan yang aman bagi pengguna. Sedangkan 1 atribut yaitu atribut ke 4 (desain spatula yang multifungsi) tidak dipertimbangkan dalam desain karena masuk kategori indifferent yang keberadaanya tidak mempengaruhi kepuasan pengguna.

Usulan desain spatula yaitu desain spatula dengan pelindung tangan, penggunaan bahan baku kayu sengon yang dikombinasikan dengan besi stainless dan menggunakan pendekatan antropometri untuk menentukan besaran dimensi desain spatula yang diusulkan. Diharapkan desain spatula mampu memberikan rasa aman dan nyaman saat digunakan oleh pengguna. Pada penelitian ini masih terbatas sampai pada desain usulan belum sampai pembuatan prototype dan kedepannya diharapkan desain diwujudkan menjadi prototype. 


\section{DAFTAR PUSTAKA}

Abdolmaleki, K., and Ahmadian, S., 2016. The relationship between product characteristics, customer and supplier involvement and new product development. Procedia economics and Finance. Vol. 36, p. 147-156.

Biglia, B., Ercis, A., and Seftap, U., 2011. Kano model application in new product development and customer satisfaction (adaptation of traditional art of tile making to jewelries). Procedia Social and Behavioral Sciences, Vol. 24, p. 829-846.

Djatna, T., Wrasiati, L.P., \& Santosa, I, B, D, Y., 2015. Balinese aromatherapy product development based on Kansei Engineering and customer personality type. Procedia Manufacturing. Vol. 4, p. 176-183.

Hasyim, A., M. and Dawal, S., Z., M., 2012. Kano model and QFD integration approach for ergonomic design Improvement. Journal Social and Behavioral Science. Vol. 57, p. 2232.

HSE, 2015. A Recipe for safety: Health and safety in food and drink manufacture. Diakses 20 Juli 2016, dari Health and Safety Excecutive Great Britain publication. Tersedia di : $\quad$ www.hse. gov.uk/pubns/priced/hsg252.pdf.
Jeong, B, H., 2015. Cooking processes and occupational accidents in commercial restaurant kitchens. Safety Science. Vol. 80, pp 87-93.

MacDonald, E., Backsell, M., Gozalez, R., and Papalambros, P., 2006. The Kano method's imperfections, and implications in product decision theory. International Design Research Symposium.

Mondal, J. A., 2012. Review on mechanical \& physical hazards at domestic kitchen. International Journal of Occupational Safety and Health. Vol. 2, No. 1, Hal. 7-10.

Narang, R. and Albayyari J., 2009. Developing product design requirements using Kano model. American Society for Engineering Education.

Rashid, M., M., 2010. A Kano model based computer system for respondents determination: Customer needs analysis for product development aspects. Management Science And Engineering. Vol. 4, No. 4, p. 7074.

Rashid, M., M., Tamaki, J., Ullah. A., M., M., S., and Kubo, A., 2010. A proposed computer system on Kano model for new product development and innovation aspect: A case study is conducted by an attractive attribute of automobile. International Journal of Engineering, Science and Technology. Vol. 2, No. 9, p. 1-12. 
Roper, S., Micheli, P., Love, J, H., \& Vahter, $\mathrm{P} . \quad 2015 . \quad$ The roles and effectiveness of design in new product development : A study of Irish manufacturers. Research Policy. Vol. 45 , p. 319-329.

Sauerwein, E., Bailom, F., Matzler, K., and Hinterhuber, H., H., 1996. The Kano model how your delight customer. International Working Seminar on Production Economics. Vol. I of the IX, p. 313-327.

Supranto, J. Statistik: Teori dan Aplikasi. Jakarta : Penerbit Erlangga, 2001.

Taifa, I., W. and Desai, D., A., 2015. Quality function deployment integration with kano model for ergonomic product improvement (classroom furniture) - A review. Journal of Multidisciplinary Engineering Science and Technology. Vol. 2, Issue 9.

Tama. I, P., Azlia, W., and Hardiningtyas, D. , 2015. Development of customer oriented product design using Kansei engineering and Kano model : Case Study Ceramic Souvenir. Proceedia Manufacturing, Vol. 4. p. 328-33.

Wang, C, H. and Hsueh, O, Z., 2013. A novel approach to incorporate customer preference and perception into product configuration: A case study on smart pads. Computer Standards \& Interfaces. Vol. 35, p. 549-556.

Wu, S., P. and Hsieh, C., S., 2002. Ergonomics study on the handle length and lift angle for the culinary spatula. Applied Ergonomics. Vol. 33, p. 493-501. 